\title{
PERANAN ANGGRAN BIAYA PRODUKSI DALAM MENINGKATKAN EFEKTIVITAS DAN EFESIENSI PENGENDALIAN BIAYA PRODUKSI PADA PT. TOLAN TIGA INDONESIA
}

\author{
${ }^{1}$ Natasya Bella Safira Marpaung, ${ }^{2}$ Sri Elviani, ${ }^{3}$ Zulkifli Siregar, ${ }^{4}$ Abdul Rasyid \\ ${ }_{1,2,3,4}$ Universitas Islam Sumatera Utara \\ ${ }^{1}$ natasyabellasafira01@gmail.com, ${ }^{2}$ srielviani@fe.uisu.ac.id, ${ }^{3}$ zulkiflisiregar051@gmail.com, \\ ${ }^{4}$ abdul.rasyid@fe.uisu.ac.id
}

\begin{abstract}
This research was conducted to see the role of the production cost budget in increasing the effectiveness and efficiency of controlling production costs at PT. Tolan Tiga Indonesia in North Sumatra. The type of data used is quantitative data. Sources of data used are primary and secondary data. Data collection methods used for this research are documentation, observation and interviews. The data analysis technique used is descriptive analysis. The results showed that the company was still less effective and efficient in carrying out production budget activities, because PT. Tolan Tiga Indonesia has not attempted to improve production cost control in order to increase its effectiveness and efficiency because there are still many levels of unfortunate or unforable variance between the relationship and the company budget. It can be seen in 2016 and 2017 the realization and production costs of PT. Tolan Tiga Indonesia in North Sumatra experienced a favorable variance where the realization rate decreased compared to the company budget. The unfavorable deviation was caused by high staff allowance expenses, increased overhead expenses, increased management expenses, increased depreciation expenses and increased third party depreciation expenses.
\end{abstract}

Keywords: production cost budge; effectivenes; efficiency; production cost control.

\begin{abstract}
ABSTRAK : Penelitian ini dilakukan untuk melihat peranan anggaran biaya produksi dalam meningkatkan efektifitas dan efesiensi pengendalian biaya produksi pada PT. Tolan Tiga Indonesia di Sumatera Utara. Jenis data yang dipakai yaitu data kuantitaif. Sumber data yang dipakai yaitu data primer dan sekunder Metode pengumpulan data yang digunakan untuk penelitian ini berupa dokumentasi, observasi dan wawancara. Teknik analisis data yang dipakai adalah analisis deskriptif. Hasil penelitian menunjukan bahwa perusahaan masih kurang efektif dan efesien dalam melakukan kegiatan anggaran produksi, dikarenakan PT. Tolan tiga indonesia belum berupaya meningkatkan pengendalian biaya produksi dalam meningkatkan efektifitas dan efesiensinya dikarenakan masih banyaknya tingkat penyimpnagan yang tidak menguntungkan atau (unforable variance) antara relasi dan anggaran perusahaan. Terlihat pada tahun 2016 dan 2017 realisasi dan biaya produksi PT. Tolan Tiga Indonesia di Sumatera Utara mengalami tingkat penyimpangan yang menguntungkan (favorable variance) dimana tingkat realisasi menurun dibandingkan anggaran perusahaan. Penyimpangan yang tidak menguntungkan disebabkan oleh tingginya beban gaji tunjangan staf, meningkatnya beban overhead, meningkatnya beban pengelolaan, meningkatnya beban penyusutan dan meningkatnya beban penyusutan pihak ke III.
\end{abstract}

Kata kunci: anggaran biaya produksi; efektifitas; efesiensi; pengendalian biaya produksi.

\section{Pendahuluan (Introduction)}

Sebuah perusahaan dalam menjalankan aktivitasnya akan berorientasi pada laba untuk mempertahankan keberadaannya dan akan terus berkembang untuk jangka waktu yang panjang dengan meningkatkan usaha yang ada sesuai dengan keadaan suatu perusahaan. "tujuan utama sebuah perusahaan yaitu menghasilkan keuntungan (laba)". Suatu usaha yang dapat dilakukan perusahaan yaitu dengan melakukan perencanaan serta pengendalian dalam kegiatan perusahaan agar perusahaan dapat berjalan secara efisien dan efektif. "Anggaran merupakan rencana kegiatan yang disusun dalam bentuk angka-angka yang sistematis 
berdasarkan ketentuan yang telah di tetapkan untuk masa yang akan datang".

Pengendalian merupakan suatu proses sistematis yang dilakukan pihak manajemen dalam mencapai suatu tujuan secara efisien dan efektif'. Pengendalian yang dilaksanakan pihak manajemen dengan membandingkan kinerja dengan rencana agar diambil suatu tindakan untuk meminimalisir kemungkinan terjadinya penyimpangan yang tidak menguntungkan pada suatu perusahaan, yang menyebabkan perusahaan tidak dapat berjalan secara efisien dan efektif. . "Suatu perusahaan jika terusmenerus semakin berkembang maka semakin banyak yang diperlukan agar tercapainya pengendalianyang lebih baik".

Menurut (mulyadi, 2009:89) menjelaskan bahwa: pengendalian merupakan usaha untuk mencapai tujuan tertentu melalui perilaku yang diharapkan". Biaya produksi "menurut mulyadi (2009:8-10) mengemukakan bahwa biaya dalam artian sempit merupakan objek yang dicatat, digolongkan, diringkas dan disajikan oleh akuntansi biaya, sedangkan biaya dalam arti luas adalah pengorbanan sumber ekonomi, yang diukur dengan satuan uang, yang telah terjadi atau kemungkinan akan terjadi untuk tujuan tertentu".

\section{Landasan Teori (Literature Review)}

\subsection{Anggaran}

Menurut (Sasungko, 2010:2) yang mendefenisikan, anggaran merupakan kebutuhan yang sangat penting bagi setiap perusahaan, baik perusahaan yang bertujuan mencari laba maupun bertujuan non laba.

\subsection{Biaya Produksi}

Menurut William, (2009), dalam bukunya akuntansi biaya yang diterjemahkan oleh krista adalah biaya produksi merupakan jumlah dari ketiga elemen biaya yaitu biaya bahan baku langsung, biaya tenaga kerja langsung, biaya overhead pabrik.

\subsection{Efektivitas}

\section{Menurut}

(Rakhmadani,

2015)

mengemukakan bahwa efektivitas merupakan pengukuran dalam arti tercapainya sasaran atau tujuan yang telah ditentukan sebelumnya, sebuah pengukuran dimana suatu target telah tercapai sesuai dengan apa yang telah direncanakan yang menekankan pentingnya efektivitas dalam pencapaian tujuan tujuan organisasi dimana efektivitas merupakan kunci dari kesuksesan suatu organisasi.

\subsection{Efesiensi}

Efisiensi merupakan kemampuan perusahaan dalam menjalankan aktivitasnya untuk memperoleh hasil tertentu dengan menggunakan masukan (input yang serendahrendahnya) untuk menghasilkan suatu keluaran (output), dan juga merupakan kemampuan untuk menyelesaikan suatu pekerjaan dengan benar.

\subsection{Pengendalian}

Menurut (Darsono \& Purwanti, 2017:10) Pengendalian adalah kegiatan yang bertujuan agar strategi, kebijakan, program kerja, dan anggaran dilaksanakan sesuai dengan yang telah ditetapkan.

\section{Metode Penelitian \\ 3.1. Objek Penelitian}

Adapun objek yang menjadi peneitian ini adalah data keuangan PT. Tolan Tiga Indonesia, yaitu data RKAP (Rencana Kerja Dan Anggaran Perusahaan).

\subsection{Jenis Data}

Jenis data yang digunakan adalah data kuantitatif. Menurut (Zuliandi Azuar, 2015:56) data kuantitatif adalah data-data yang berwujud angka-angka tertentu, yang dapat dioperasikan secara sistematis.

\subsection{Teknik Perolehan Data}

1. Metode Dokumentasi, Yaitu Mengumpulkan Data - Data Yang Berhubungan Dengan Anggaran Biaya Produksi Perusahaan Yang Dianggap Penulis Penting.

2. Observasi, Berupa Melakukan Pengamatan Langsung Terhadap Objek Yang Penelitian, Yaitu Laporan Anggaran Dan Realisasinya.

3. Wawancara, Yaitu Melakukan Tanya Jawab Langsung Terhadap Objek Penelitian Berupa Tentang Laporan Anggaran Dan Realisasinya.

\subsection{Teknik Analisis Data}

Menurut mengatakan bahwa analisis deskriptif merupakan menganalisis data untuk permasalahan variabel-variabel mandiri dan tidak bermaksud untuk menganalisis hubungan atau keterkaitan antar variabel. 


\section{Hasil Penelitian/Temuan (Findings)}

Tabel 1. Laporan Selisih Biaya Produksi Kelapa Sawit Per/31 Desember 2015

\begin{tabular}{lcr}
\hline \multirow{2}{*}{ URAIAN } & \multicolumn{2}{c}{ SELISIH } \\
\cline { 2 - 3 } & \multirow{2}{*}{ Kg } & \multicolumn{1}{c}{$\begin{array}{c}\text { Biaya } \\
(\mathrm{Rp})\end{array}$} \\
\hline Beban Gaji Tunjangan Staf & $(40.369 .200)$ & 6.899 .700 .000 \\
B. Pemeliharaan Tan. Menghasilkan & & 71.300 .000 .000 \\
Beban Pemupukan & & 160.704 .283 .000 \\
Beban Panen & & $(4.800 .390 .000)$ \\
Beban Pengangkutan Ke Pabrik & & 39.500 .080 .000 \\
Beban Overhead & $(40.369 .200)$ & 278.303 .193 .000 \\
Jumlah Beban Tanaman & & 131.638 .599 .000 \\
Beban Pengolaan & & 409.942 .392 .000 \\
Beban Produk Excl.Penyusutan & $(40.369 .200)$ & 19.500 .150 .000 \\
Beban Penyusutan Overhead & $(40.369 .200)$ & 14.750 .120 .000 \\
Beban Penyusutan Pengelolaan & 444.192 .662 .000 \\
Beban Prod. Incl. Penyusutan Kebun Sendiri & & 13.999 .080 .000 \\
Beban Pembelian Produksi Pihak III & $(3.400 .010)$ & 1.800 .020 .000 \\
Beban Pengolaan Pihak III & & 15.799 .100 .000 \\
Beban Produksi Pihak III & & 459.991 .762 .000 \\
Jumlah Beban Produksi Kebun & $(43.769 .210)$ & 13.399 .407 .000 \\
Beban Olah IS Menjadi PKO Dan PKM & $(4.499 .890)$ & \\
\hline Beban Jumlah Produksi Kebun & $(48.269 .100)$ & 401.890 .655 .000 \\
\hline \multicolumn{1}{c}{ Sumber: PT. Tolan Tiga Indonesia } & &
\end{tabular}

Pada periode 2015 dapat dilihat bahwa realisasi berada diatas biaya yang sudah di tetapkan atau dianggarkan perusahaan yaitu sebesar Rp.4.283.264.396.000 atau 10,35\% dari yang dianggarkan sebesar Rp.3.881.373.741.000 dengan kuantitas produksi $779.356 .920 \mathrm{Kg}$.

Pada periode ini ada beberapa biaya diatas anggaran yang telah ditetapkan perusahaan

Tabel 2. Laporan Selisih Biaya Produksi Kelapa Sawit Per/31 Desember 2016

\begin{tabular}{|c|c|c|}
\hline \multirow{2}{*}{ URAIAN } & \multicolumn{2}{|c|}{ SELISIH } \\
\hline & $\mathrm{Kg}$ & Biaya \\
\hline Beban Gaji Tunjangan Staf & $(39.889 .890)$ & $(2.799 .500 .000)$ \\
\hline B. Pemeliharaan Tan. Menghasilkan & & $(27.799 .780 .000)$ \\
\hline Beban Pemupukan & & $(40.200 .130 .000)$ \\
\hline Beban Panen & & $(86.599 .720 .000)$ \\
\hline Beban Pengangkutan Ke Pabrik & & 50.830 .400 .000 \\
\hline Beban Overhead & & 4.630 .020 .000 \\
\hline Jumlah Beban Tanaman & $(39.889 .890)$ & $(101.938 .710 .000)$ \\
\hline Beban Pengolaan & & $(12.899 .950 .000)$ \\
\hline Beban Produk Excl.Penyusutan & & $(114.838 .660 .000)$ \\
\hline Beban Penyusutan Overhead & $(39.889 .890)$ & $(1.599 .630 .000)$ \\
\hline Beban Penyusutan Pengelolaan & $(39.889 .890)$ & 18.480 .120 .000 \\
\hline Beban Prod. Incl. Penyusutan Kebun Sendiri & & $(97.958 .170 .000)$ \\
\hline Beban Pembelian Produksi Pihak III & $(65.030 .030)$ & $(79.320 .482 .000)$ \\
\hline Beban Pengolaan Pihak III & & $(5.500 .080 .000)$ \\
\hline Beban Produksi Pihak III & & $(84.820 .562 .000)$ \\
\hline
\end{tabular}

yaitu "beban gaji tunjangan staf $11,70 \%$, beban pengangkutan ke pabrik $21,84 \%$, beban overhead

$2,53 \%$, beban pengelolaan $54,73 \%$, beban penyusutan pengolaan $12,22 \%$, beban pembelian produksi pihak ke III $0,83 \%$, dan beban pengolaan pihak ke III $1,25 \%$ diatas RKAP". 


\begin{tabular}{|c|c|c|}
\hline \multirow{2}{*}{ URAIAN } & \multicolumn{2}{|c|}{ SELISIH } \\
\hline & $\mathrm{Kg}$ & Biaya \\
\hline Jumlah Beban Produksi Kebun & $(104.919 .920)$ & $(182.778 .732 .000)$ \\
\hline Beban Olah IS Menjadi PKO Dan PKM & $(3.086 .320)$ & $(23.440 .170 .000)$ \\
\hline Beban Jumlah Produksi & $(101.833 .600)$ & $(263.679 .202 .000)$ \\
\hline
\end{tabular}

Pada periode 2016 dapat dilihat bahwa realisasi kelapa sawit dibawah anggaran yang di tetapkan atau di anggarkan oleh perusahaan yaitu sebesar Rp.3.909.793.283.000 atau 6,32\% dari yang dianggarkan sebesar Rp.4.173.472.485.000 dengan kuantitas produksi $731.882 .540 \mathrm{Kg}$. Pada periode ini terlihat biaya produksi kelapa sawit yaitu

Tabel 3. Laporan Selisih Biaya Produksi Kelapa Sawit Per/31 Desember 2017

\begin{tabular}{lrr}
\hline \multirow{1}{*}{ URAIAN } & \multicolumn{2}{c}{ SELISIH } \\
\cline { 2 - 3 } & \multirow{2}{*}{ Kg } & \multicolumn{1}{c}{$\begin{array}{c}\text { Biaya } \\
(\mathrm{Rp})\end{array}$} \\
\hline Beban Gaji Tunjangan Staf & $(16.894 .830)$ & $(2.499 .880 .000)$ \\
B. Pemeliharaan Tan. Menghasilkan & & $(225.429 .940 .000)$ \\
Beban Pemupukan & & 30.199 .950 .000 \\
Beban Panen & & $(59.999 .890 .000)$ \\
Beban Pengangkutan Ke Pabrik & & 130.200 .000 .000 \\
Beban Overhead & $(16.894 .830)$ & $(115.149 .740 .000)$ \\
Jumlah Beban Tanaman & & $(22.099 .950 .000)$ \\
Beban Pengolaan & & $(137.249 .690 .000)$ \\
Beban Produk Excl.Penyusutan & $(16.894 .830)$ & 16.000 .215 .000 \\
Beban Penyusutan Overhead & $(41.919 .910)$ & 29.579 .970 .000 \\
Beban Penyusutan Pengelolaan & & $(91.669 .505 .000)$ \\
Beban Prod. Incl. Penyusutan Kebun Sendiri & & $(143.169 .325 .000)$ \\
Beban Pembelian Produksi Pihak III & $(112.464 .820)$ & $(8.522 .383 .000)$ \\
Beban Pengolaan Pihak III & & $(151.691 .708 .000)$ \\
Beban Produksi Pihak III & & $(129.359 .650)$ \\
Jumlah Beban Produksi Kebun & $(243.361 .213 .000)$ \\
Beban Olah IS Menjadi PKO Dan PKM & $(5.137 .870)$ & $(14.819 .470 .000)$ \\
\hline Beban Jumlah Produksi & & \\
\hline \multicolumn{1}{c}{ Sumber: PT. Tolan Tiga Indonesia } & & $(344.882 .183 .000)$ \\
\hline
\end{tabular}

Pada periode 2017 dapat dilihat bahwa realisasi kelapa sawit dibawah anggaran yang di tetapkan atau di anggarkan oleh perusahaan yaitu sebesar Rp.3.839.922.675.000 atau 8,24\% dari yang dianggarkan sebesar Rp.4.184.804.858.000 dengan kuantitas produksi $712.770 .900 \mathrm{Kg}$. Pada periode ini terlihat biaya produksi kelapa sawit dari periode sebesar

(Rp.4.173.472.485.000

Rp.3.909.793.283.000) sebelumnya, pada tahun ini hanya ada satu biaya yang berada diatas anggaran yang di tetapkan perusahaan yaitu "beban penyusutan pengolaan sebesar 18,06\% diatas RKAP”.
Rp.263.679.202.000 dari periode di 


\begin{tabular}{lcr}
\hline \multirow{1}{*}{ URAIAN } & \multicolumn{2}{c}{ SELISIH } \\
\cline { 2 - 3 } & $\mathrm{Kg}$ & \multicolumn{1}{c}{$\begin{array}{c}\text { Biaya } \\
(\mathrm{Rp})\end{array}$} \\
\hline Beban Pemupukan & & 72.500 .050 .000 \\
Beban Panen & & 23.320 .020 .000 \\
Beban Pengangkutan Ke Pabrik & & 26.359 .840 .000 \\
Beban Overhead & $(14.945 .080)$ & 5.129 .900 .000 \\
Jumlah Beban Tanaman & & 162.849 .100 .000 \\
Beban Pengolaan & & 99.720 .210 .000 \\
Beban Produk Excl.Penyusutan & $(14.945 .080)$ & 16.229 .380 .000 \\
Beban Penyusutan Overhead & $(14.945 .080)$ & 14.109 .910 .000 \\
Beban Penyusutan Pengelolaan & & 292.908 .600 .000 \\
Beban Prod. Incl. Penyusutan Kebun Sendiri & $(52.189 .870)$ & 13.999 .080 .000 \\
Beban Pembelian Produksi Pihak III & & 22.596 .942 .000 \\
Beban Pengolaan Pihak III & & 36.596 .022 .000 \\
Beban Produksi Pihak III & $(67.134 .950)$ & 329.504 .622 .000 \\
Jumlah Beban Produksi Kebun & 4.260 .130 & 79.739 .480 .000 \\
Beban Olah IS Menjadi PKO Dan PKM & $(71.395 .080)$ & 409.244 .102 .000 \\
\hline Beban Jumlah Produksi & & \\
\hline \multicolumn{1}{c}{ Sumber: PT. Tolan Tiga Indonesia } & &
\end{tabular}

Pada periode 2018 dapat dilihat bahwa realisasi kelapa sawit berada diatas anggaran yang di tetapkan atau di anggarkan oleh perusahaan yaitu sebesar Rp.5.403.883.220.000 atau $8,19 \%$ dari yang dianggarkan sebesar Rp.4.994.589.118.000 dengan kuantitas produksi $754.490 .870 \mathrm{Kg}$. Pada periode ini terlihat biaya produksi kelapa sawit dari periode

sebelumnya atau periode 2018 mengalami kenaikan produksi kelapa sawit yaitu sebesar Rp.409.294.102.000 (Rp.5.403.883.220.000 Rp.4.994.589.118.000) dari periode sebelumnya, pada periode ini terdapat dua biaya diatas anggaran yaitu "beban pengolaan $26.20 \%$ dan beban penyusutan beban overhead $9,39 \%$ diatas RKAP".

Tabel 5. Laporan Selisih Biaya Produksi Kelapa Sawit

Per/31 Desember 2019

\begin{tabular}{lcr}
\hline \multirow{2}{*}{ URAIAN } & \multicolumn{2}{c}{ SELISIH } \\
\cline { 2 - 3 } & Kg & \multicolumn{1}{c}{$\begin{array}{c}\text { Biaya } \\
(\mathrm{Rp})\end{array}$} \\
\hline Beban Gaji Tunjangan Staf & $(7.929 .900)$ & 2.480 .790 .000 \\
B. Pemeliharaan Tan. Menghasilkan & & 40.499 .240 .000 \\
Beban Pemupukan & & 100.100 .050 .000 \\
Beban Panen & & 10.029 .670 .000 \\
Beban Pengangkutan Ke Pabrik & & 18.330 .220 .000 \\
Beban Overhead & $(7.929 .900)$ & 20.060 .150 .000 \\
Jumlah Beban Tanaman & & 781.500 .120 .000 \\
Beban Pengolaan & & 269.549 .900 .000 \\
Beban Produk Excl.Penyusutan & 22.070 .100 & 25.480 .510 .0000 \\
Beban Penyusutan Overhead & & 15.990 .190 .000 \\
Beban Penyusutan Pengelolaan & $(13.009 .700)$ & 311.020 .720 .000 \\
Beban Prod. Incl. Penyusutan Kebun Sendiri & 174.340 .250 .000 \\
Beban Pembelian Produksi Pihak III & & 14.431 .775 .000 \\
Beban Pengolaan Pihak III & & 188.772 .025 .000 \\
Beban Produksi Pihak III & & \\
Jumlah Beban Produksi Kebun & & \\
Beban Olah IS Menjadi PKO Dan PKM & 3.260 .330 & 79.750 .400 .000 \\
\hline Beban Jumlah Produksi & $(24.199 .930)$ & 579.543 .145 .000 \\
\hline \multicolumn{1}{c}{ Sumber: PT. Tolan Tiga Indonesia } & &
\end{tabular}


Pada periode 2019 dapat dilihat bahwa realisasi kelapa sawit berada diatas anggaran yang di tetapkan atau di anggarkan oleh perusahaan yaitu sebesar Rp.4.623.802.073.000 atau $14,33 \%$ dari yang dianggarkan sebesar Rp.4.044.258.928.000 dengan kuantitas produksi $845.061 .390 \mathrm{Kg}$. Pada periode ini terlihat biaya produksi kelapa sawit dari periode sebelumnya atau periode 2017 mengalami Tabel 6 Laporan Rasio Efektivitas dan Efesiensi Anggaran Biaya Produksi Kelapa Sawit PT. Tolan Tiga Indonesia

\begin{tabular}{|c|c|c|c|c|c|}
\hline Tahun & Anggaran & Realisasi & Selisih & $\begin{array}{c}\text { Rasio } \\
\text { Efektivitas }\end{array}$ & $\begin{array}{c}\text { Rasio } \\
\text { Efesiensi }\end{array}$ \\
\hline 2015 & 3.859 .022 .891 .000 & 4.319 .014 .653 .000 & -459.991 .762 .000 & $1,12 \%$ & $-0,89 \%$ \\
\hline 2016 & 4.121 .302 .165 .000 & 3.938 .523 .433 .000 & 182.778 .732 .000 & $-0,96 \%$ & $1,05 \%$ \\
\hline 2017 & 4.126 .634 .638 .000 & 3.883 .273 .425 .000 & 756.638 .371 .000 & $-0,94 \%$ & $1,06 \%$ \\
\hline 2018 & 4.553 .768 .478 .000 & 4.883 .273 .100 .000 & -329.504 .662 .000 & $1,07 \%$ & $-0,93 \%$ \\
\hline 2019 & 3.663 .778 .578 .000 & 4.163 .571 .323 .000 & -449.792 .745 .000 & $1,14 \%$ & $-0,88 \%$ \\
\hline
\end{tabular}

Dari tabel 6 diatas dapat diketahui hasil perhitungan rasio efektivitas anggaran biaya produksi pada PT. Tolan Tiga Indonesia pada tahun 2015 sebesar 1,12\%, tahun 2016 terjadi penurunan sebesar $-0,96 \%$, tahun 2017 terjadi penurunan kembali sebesar $-0,94 \%$, tahun 2018 mengalami kenaikan sebesar 1,07\%, tahun 2019 mengalami kenaikan kembali sebesar 1,14\%.

Dari tabel 6. Diatas dapat diketahui hasil perhitungan rasio efesiensi anggaran biaya produksi pada PT. Tolan Tiga Indonesia tahun 2015 sebesar $-0,89 \%$, tahun 2016 mengalami kenaikan sebesar 1,05\%, tahun 2017 mengalami kenaikan kembali sebesar 1,06\% tahun 2018 mengalami penurunan sebesar $-0,93 \%$, tahun 2019 mengalami kenaikan kembali sebesar $-0,88 \%$.

1) Pengendalian Biaya Produksi Periode 2015

Pengendalian biaya produksi yang meliputi pengendalian seluruh total biaya produksi yang mencakup biaya tanam, pengelolaan, penyusutan dan pembelian. Besarnya realisasi periode 2015 sebesar Rp.5.495,90/Kg atau dengan total biaya produksi sebesar Rp.4.283.264.396.000 dengan kuantitas $779.356 .920 \mathrm{Kg}$.

Anggaran biaya produksi kelapa sawit Rp. 3. 881.373.741.000

Realisasi anggaran biaya produksi kelapa sawit Rp. 4.283.264.396.000 Biaya anggaran produksi kelapa sawit perode 2015 dengan selisih Rp.401.890.655.000 berupa penyimpangan tidak menguntungkan (unfavorable kenaikan produksi kelapa sawit yaitu sebesar Rp.579.543.145.000 (Rp.4.623802073.000 Rp.4.004.258.928.000) dari periode sebelumnya, pada periode ini terdapat tiga biaya diatas anggaran yaitu "beban pengolaan $30,96 \%$, beban penyusutan beban overhead $17,30 \%$, dan beban penyusutan pengelolaan $14,50 \%$ diatas RKAP".

variance). Realisasi biaya produksi 2015 berada diatas anggaran.

2) Pengendalian Biaya Produksi Periode 2016 Pengendalian biaya produksi meliputi pengendalian seluruh total biaya produksi yang mencakup biaya tanam,pengelolaan, penyusutan dan pembelian. Besarnya realisasi biaya produksi periode 2016 sebesar Rp.5.342,10/Kg dengan jumlah biaya produksi sebesar Rp.3.909.793.283.000 dengan kuantitas $731.882 .540 \mathrm{Kg}$.

Anggaran biaya produksi kelapa sawit Rp. 4.173.472.485.000

Realisasi anggaran biaya produksi kelapa sawit Rp. 3.909.793.283.000

Biaya anggaran produksi kelapa sawit perode 2016 dengan selisih Rp.263.579.202.000 berupa penyimpangan menguntungkan (favorable). Realisasi biaya produksi periode 2016 berada dibawah anggaran.

3) Pengendalian Biaya Produksi Periode 2017 Pengendalian biaya produksi meliputi pengendalian seluruh total biaya produksi yang mencakup biaya tanam, pengelolaan, penyusutan dan pembelian. Besarnya realisasi biaya produksi periode 2017 sebesar Rp. 5.387,32/Kg dengan jumlah biaya produksi- sebesar Rp.3.839.922.675.000 dengan kuantitas $712.770 .900 \mathrm{Kg}$.

Anggaran biaya produksi kelapa sawit Rp.4.184.804.858.000 
Realisasi anggaran biaya produksi kelapa sawit Rp.3.839.922.675.000

Biaya anggaran produksi kelapa sawit perode 2017 dengan selisih Rp.344.882.183.000 berupa penyimpangan menguntungkan (favorable). Realisasi Biaya Produksi Periode 2017 Berada Dibawah Anggaran.

4) Pengendalian Biaya Produksi Periode 2018 Pengendalian biaya produksi secara keseluruhan yang meliputi pengendalian keseluruhan total biaya produksi yang mencakup biaya tanam, biaya pengelolaan, biaya penyusutan dan biaya pembelian. Besarnya realisasi biaya produksi kelapa sawit periode 2018 adalah sebesar Rp.7.162,22/Kg atau dengan total biaya produksi sebesar Rp.5.403.833.220.000 dengan kuantitas $754.490 .870 \mathrm{Kg}$.

Anggaran biaya produksi kelapa sawit

$$
\text { Rp.4.994.589.118.000 }
$$

Realisasi anggaran biaya produksi kelapa sawit Rp.5.403.833.220.000

Biaya anggaran produksi kelapa sawit perode 2018 dengan selisih Rp.409.244.102.000 merupakan penyimpangan yang tidak menguntungkan (unfavorable variance). Realisasi biaya produksi pengolahan kelapa sawit periode 2018 berada diatas anggaran.

5) Pengendalian Biaya Produksi Periode 2019 Pengendalian biaya produksi meliputi pengendalian keseluruhan total biaya produksi yang mencakup biaya tanam, pengelolaan, penyusutan dan a pembelian. Besarnya realisasi biaya produksi periode 2018 sebesar Rp.5.471,56/Kg dengan jumlah biaya produksi sebesar Rp.4.623.802.073.000 dengan kuantitas $845.061 .390 \mathrm{Kg}$.

Anggaran Biaya Produksi Kelapa Sawit Rp. 4.044.258.928.000

Realisasi Anggaran Biaya Produksi Kelapa Sawit Rp. 4.623.802.073.000

Biaya anggaran produksi kelapa sawit perode 2018 dengan selisih Rp.579.543.145.000 berupa penyimpangan tidak menguntungkan (unfavorable variance). Realisasi biaya produksi periode 2019 berada diatas anggaran.

\section{Kesimpulan (Conclusions)}

Setelah dilakukan analisis dan evaluasi mengenai "peranan anggaran biaya produksi dalam meningkatkan efektivitas dan efesiensi pengendalian biaya produksi pada PT. Tolan Tiga Indonesia di Sumatera Utara" maka kesimpulan yang dapat diambil adalah sebagia berikut:

1) PT. Tolan Tiga Indonesia di Sumatera Utara realisasi biaya produksi pengelolaan kelapa sawit dari periode 2015 sampai dengan periode 2019 menunjukkan bahwa perusahaan masih kurang efektif dan efisien dalam melakukan kegiatan anggaran produksi.

2) PT. Tolan Tiga Indonesia di Sumatera Utara belum berupaya meningkatkan pengendalian anggaran produksi dalam meningkatkan efektivitas dan efesiensinya dikarenakan masih banyaknya tingkat penyimpangan yang tidak menguntungkan (unforable variance) antara realisasi dengan anggaran perusahaan.

3) Terlihat pada tahun 2016 dan 2017 realisasi dan biaya produksi PT. Tolan Tiga Indonesia di Sumatera Utara mengalami tingkat penyimpangan yang menguntungkan (favorable variance) dimana tingkat realisasi menurun dibandingkan anggaran perusahaan.

4) Dari periode 2015 sampai periode 2019 terdapat realisasi biaya produksi pengelolaan kelapa sawit PT. Toalan Tiga Indonesia di Sumatera Utara berada diatas anggaran yang sudah ditetapkan perusahaan disebabkan tingginya beban gaji tunjangan staf, meningkatnya beban overhead, meningkatnya beban pengelolaan, meningkatnya beban penyusutan dan meningkatnya beban penyusutan pihak ketiga.

5) Dari data periode 2015 sampai dengan periode 2019 biaya rata-rata realisasi biaya produksi pengelolaan kelapa sawit PT. Tolan Tiga Indonesia berada dibawah anggaran atau RKAP perusahaan.

\section{DAFTAR PUSTAKA (REFERENCES)}

Afifah, U. Z. (2017). Anggaran Sebagai Alat Pengendalian Kinerja Pada PT Asuransi Kredit Indonesia (Askrindo) Cabang Jember Periode 2014-2016 (Budget as Performance Control Tool at Asuransi Kredit Indonesia Ltd. (ASKRINDO) of Jember Branch in 2014-2016 Period. Jurnal E-SOSPOL Volume IV Edisi 2, Mei - Agustus 2017.

Ahsan Barus. (2019). analisis anggaran sebagai upaya dalam perencanaan dan pengendalian 
biaya proyek pada pt $\mathrm{X}$ di kota ambon. Jurnal Ekonomi, Sosial \& Humaniora 2019.

Cecep Hamzah Pansuri. (2017). Peranan Penyusunan Anggaran Biaya Produksi Dalam Menunjang Efektivitas Pengendalian Biaya Produksi Pada PT. Elco Indonesia Sejahtera Garut. Jurnal Wacana Ekonomi, Fakultas Ekonomi Universitas Garut. Vol. 16 No. 02, Tahun 2017.

Dahrin. (2018). Manfaat anggaran biaya produksi dalam menunjang efektivitas pengendalian biaya produksi pada PTPN V Sei Rokan. Jurnal Artikel Text 2019.

Darsono, \& Purwanti, A. (2017). Penganggaran Perusahaan (Edisi 2). mitra wacana media.

mulyadi. (2009). Akuntansi Biaya. Aditia Media.

Rahmawaty M. Bumulo. (2018). Analisis Efektivitas Penggunaan Anggaran Sebagai Alat Pengendalian Belanja Langsung Pada Biro Hukum Provinsi Sulawesi Utara. Jurnal Riset Akuntansi Going Concern 13(4), 2018.

Rakhmadani. (2015). Analisis Anggaran Biaya Produksi Sebagai Alat Pengendalian Biaya Produksi Pada PT. Perkebunan Nusantara IV (PERSERO) Medan. Jurnal Riset Akuntansi Dan Bisnis, Universitas Muhammadiyah Sumatera Utara. Vol 15 No. 1, Maret 2015.

Raquel Amelia Saipi. (2018). Analisis Anggaran Kas Sebagai Alat Perencanan Dan Pengendalian Kas Pada PT Pelabuhan Indonesia IV Cabang Bitung. Jurnal Riset Akuntansi Going Concern 13(2), 2018.

Rhika Sevina. (2016). Analisis Anggaran Sebagai Biaya Produksi Pada PTPN V Pabrik Kelapa Sawit Sei Pagar Kecamatan Perhentian Raja Kabupaten Kampar. Jurnal Analisis Anggaran Sebagai Perencanaan 2016.

Sasungko, C. dan S. R. P. (2010). Anggaran. Salemba Empat.

William, C. K. (2009). Akuntansi Biaya. Edisi 14.

Zuliandi Azuar. (2015). Metodologi Penelitian Bisnis. UMSU PRESS. 